\title{
Giant intraosseous meningioma mimicking fibrous dysplasia
}

\author{
Karen Micol Huscher,' Christian Öhlschlegel, Doortje Caroline Engel, Jean Yves Fournier \\ Department of Neurosurgery/Pathology Cantonal Hospital St. Gallen, St. Gallen, Switzerland
}

Received: January 14, 2016 Accepted: February 25, $2016 \quad$ Online Published: March 9, 2016

DOI: $10.5430 /$ crcp.v3n2p29 URL: http://dx.doi.org/10.5430/crcp.v3n2p29

\begin{abstract}
We illustrate a case of a giant primary intraosseous meningiomas (PIMs) with optic nerve compression treated by partial resection. A 48-year-old female presented with visual disturbances exophthalmus, diplopia and eye pain due to optic nerve compression. The patient had a past history of fibrous dysplasia treated surgically with partial resection by ENT in 2010. Histology confirmed the diagnosis. Two years later she presented with further decrease in visual acuity and diffuse hyperostosis. In this context she underwent a neurosurgical procedure consisting in craniotomy and further partial resection of the lesion including optic canal decompression. The second pathological examination demonstrated an extensive meningioma (WHO grade I) of the skull base.

We recommend that in cases of diffuse hyperostosis the differential diagnosis include diffuse intraosseous meningioma. If complete surgical resection is not achievable, a biopsy to confirm the diagnosis is recommended. Treatment options include complete or partial resection followed by adjuvant radiotherapy.
\end{abstract}

Key Words: Skull base, Meningioma, Hyperostosis, Fibrous dysplasia

\section{CASE REPORT}

A 48-year-old woman presented with a 3-year history of progressive right sided visual disturbance, exophthalmus, diplopia and eye pain. The patient underwent a cranial CT scan which showed a diffuse bilateral frontal and skull base hyperostosis, especially evident on the right side, and extending bilaterally from the sphenoid bones, down to the clinoid processes, orbits, temporal bones and the right frontal bone as seen in Figure 1. The right optic nerve was displaced with narrowing of the optic canal. These findings were consistent with fibrous dysplasia. Diffuse hyperostosis could also be consistent with an osteosarcoma, although this was less likely. The mass effect of the tumor involving both orbits caused compression of the eye muscles with subsequent exophthalmos, also more evident on the right side. The gen- eral practitioner referred the patient to an ophthalmologist who diagnosed exophthalmos with compressive optic nerve atrophy, decreased vision and secondary glaucoma. The ophthalmologist then referred the patient to an ENT doctor.

The patient underwent surgical decompression of the right orbit via a transethmoidal, transsphenoidal and transpalpebral approach. During the operation, visualization of the orbital content was inadequate and bleeding from the bone prevented completion of the planned operation. The ENT suggested a second operation via a right subfrontal craniotomy to further decompress the orbit and the optic nerve. The first histopathological analysis seemed to confirm the suspicion of fibrous dysplasia and the patient was discharged. Ophthalmological and radiological follow-up was conducted via CT and MRI.

\footnotetext{
*Correspondence: Karen Micol Huscher; Email: karen.huscher@ gmail.com; Address: Department of Neurosurgery/Pathology Cantonal Hospital St. Gallen, St. Gallen, Switzerland.
} 


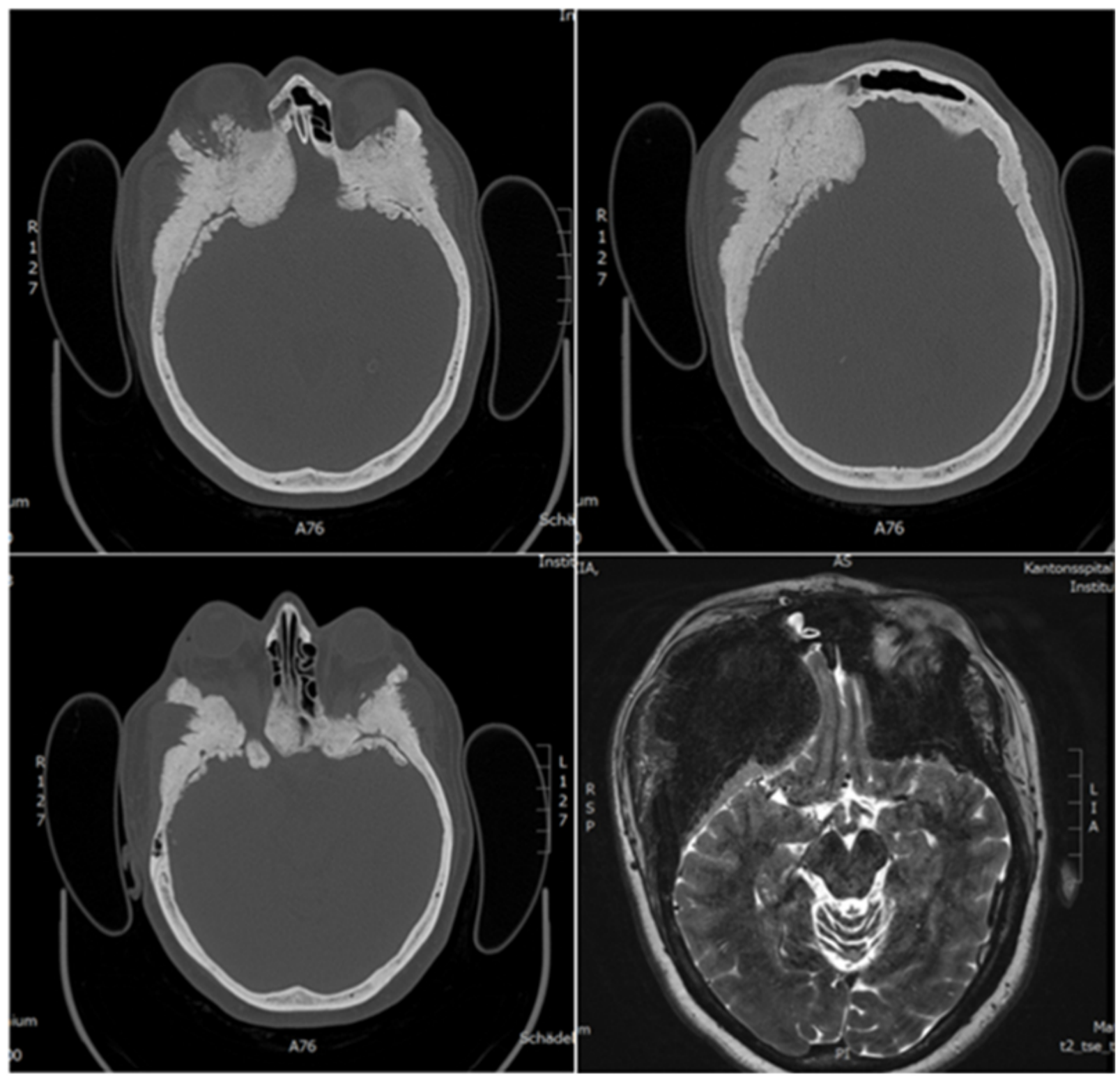

Figure 1. Radiological imaging: Computer Tomography showing diffuse hyperostosis (meningioma) of the skull base predominantly right with narrowing of the right optic canal. Bone window demonstrates bone hyperplasia. On $\mathrm{T} 2$ weighted MRI impressive compression of the olfactory cortex.

Two years later the patient demonstrated identical clinical symptoms with further visual loss. A repeat cranial CT was performed and showed considerably increased hyperostosis of the skull base and especially of the right optic canal. On this occasion the patient was referred to the neurosurgical department and underwent a right pterional craniotomy with decompression of the optic canal through the intraorbital space and a cranioplasty. The operation lasted 6.5 hours and, apart an estimated blood loss of $1.5 \mathrm{~L}$ was uneventful. On this occasion, the histopathological results unexpectedly showed the presence of meningioma cells with a proliferation index of MIB- $1<1 \%$. Fibrous dysplasia was excluded using immunohistochemical analysis which revealed positivity to EMA, Vimentin and progesterone receptors (see Figure 2). The old slides were revisited. revealing that the initial diagnosis of fibrous dysplasia had been incorrect. Retrospectively, the first slides also showed meningioma cells which had not been observed due to the omission on immunohistochemical analysis.

Postoperative imaging showed partial bone-resection and a wide optic canal with the persistence of hyperostosis. Further resection was not considered an option as, even without the above-mentioned circumstances, a complete resection would not have been feasible due to extensive skull base invasion. 
The case was discussed at the neurosurgical tumour board conference and radiation therapy was recommended to avoid further progression/growth of the lesion.

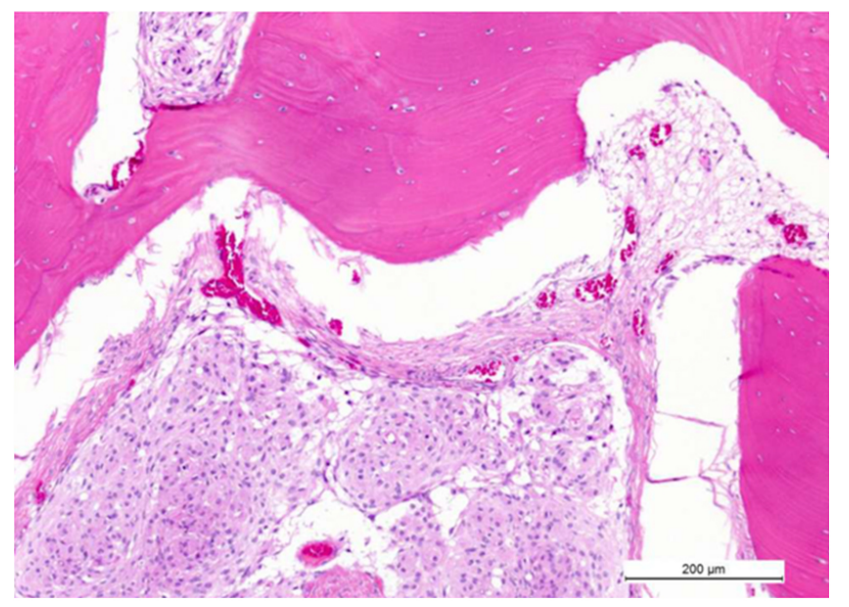

Figure 2. Pathological examination on eosinophilic stain. In soft pink from the edge to the middle of the picture are shown the meningioma cells. They express epithelial membrane antigen (EMA), vimentin and progesterone receptors which confirm meningothelial differentiation and exclude fibrous dysplasia.

\section{Discussion}

Meningiomas are benign neoplasms of meningothelial cells and present in the subdural space as primary intradural meningiomas. Occurrence outside of the central nervous system is called ectopic. The classification of these lesions is based on the presence (primary lesion) or absence (secondary lesion) of a connection with the central nervous system. The following ectopic locations of meningiomas have been reported: skull, ${ }^{[1-3]}$ scalp, ${ }^{[4]}$ orbit,${ }^{[5]}$ paranasal sinuses,${ }^{[6]}$ nasopharynx,${ }^{[6,7]}$ neck ${ }^{[8,9]}$ and skin; ${ }^{[10,11]}$ occasionally in the lung, ${ }^{[12]}$ mediastinum, ${ }^{[13]}$ adrenal gland, ${ }^{[9]}$ paraspinal region, ${ }^{[14]}$ and even in a finger. ${ }^{[10]}$ These primary extradural meningiomas (PEM) are rare tumours accounting for less than $2 \%$ of all meningiomas. The most common sites of occurrence of the ectopic meningiomas of the head and neck region include the middle ear and temporal bone, sinonasal cavity, orbit, oral cavity, and parotid gland. ${ }^{[11,12]}$ Common symptoms of sinonasal cavity meningiomas are nasal obstruction, epistaxis, headache, pain, visual disturbances and facial deformity. The tumours may erode the bone of the sinuses and the surrounding soft tissues, the orbit and the skull base. ${ }^{[12]}$ The invasion of bones by meningiomas through osseous canaliculi is not a sign of malignancy. ${ }^{[13]}$

Primary extradural meningiomas are rare lesions and this term indicates that the origin of these tumours is not the dura. It is crucial to distinguish these meningiomas from primary intraosseous meningiomas (PIMs), which may have

Published by Sciedu Press secondary extracranial extensions and/or may have metastasized. The term PEM refers to those lesions arising within the calvaria, which are not included in the term "extracranial meningioma". This term, PEM, also eliminates any confusion caused by using the term "ectopic meningioma", which includes primary meningiomas located within the ventricular system.

These shortcomings have resulted in limited knowledge of the biological and clinical behaviour of meningiomas arising outside the subdural compartment.

In order to develop a better understanding of these tumours and to establish a comprehensive classification scheme for them, Lang et al. ${ }^{[24]}$ analysed a series of patients from the M.D. Anderson Cancer Centre (MDACC) and reviewed all cases reported in the literature since the use of CT scanning. They concluded that the definition of "PEM" (Primary Extradural Meningioma) reflects the tumour's relation to the dura mater and the extent and direction of its growth, and that the classification of PEMs as calvarial or extracalvarial and as convexity or skull base lesions correlates with clinical outcome.

Purely extracalvarial tumours are Type I, purely calvarial tumours are Type II, and calvarial tumours with extracalvarial extension are Type III. Each category is further classified into convexity (C) or skull base (B) subtypes based on their anatomical location. So, intraosseous meningiomas could be considered Type II or III primary extradural meningiomas based on whether extracalvarial extension is observed. According to these data our case can be classified as Type III B. (see Table 1)

Table 1. Classification scheme of primary extradural meningiomas. Adapted from Lang and colleagues. ${ }^{[24]}$

\begin{tabular}{lll}
\hline Type & Description & Subclassification \\
\hline I & Purely extracalvarial & Not applicable \\
II & Purely calvarial & B (skull base) \\
& & C (convexity) \\
III & Calvarial with extracalvarial extension & B (skull base) \\
& & C (convexity) \\
\hline
\end{tabular}

According to the literature ${ }^{[15]}$ this special type of osteoblastic intraosseous meningioma may appear radiologically similar to a fibrous dysplasia; further differential diagnosis will be discussed in the following section.

\subsection{Diagnosis}

PIMs deserve special consideration: they can be osteoblastic, osteolytic, or mixed on CT scans and radiographs of the skull. Conventional cranial radiography shows anomalies such as typical hair-on.end appearance of the skull in 30\%-60\% of 
cases. $^{[24]} \mathrm{CT}$ is more sensitive and pointed out an hyperdense focal thickened expansive lesion of the skull. In most cases, intraosseous meningiomas are osteoblastic, showing a local bony expansion and a radiological "ground glass" appearance similar to fibrous dysplasia. ${ }^{[25]}$ Rarely PIMs may present as an osteolytic skull lesion. ${ }^{[18,22]}$ The osteoblastic subtype may be mimicked by other entities that appear as a focal hyperdense lesion on CT, including meningioma "en plaque", osteoma, osteosarcoma, Paget disease, and fibrous dysplasia. ${ }^{[15,21]}$ Clinical informations and radiologic details can further guide the differential diagnosis.

The osteolytic subtype of intraosseous meningioma requires a differential diagnosis for solitary osteolytic skull lesions such as haemangioma, chondroma, chondrosarcoma, dermoid tumour, epidermoid tumour, hemangiopericytoma, brown tumour, multiple myeloma, plasmacytoma, giant cell tumour, aneurysmal bone cyst, eosinophilic granuloma, or metastatic cancer. ${ }^{[16,17,19,20,22]}$

Magnetic resonance imaging (MRI) shows similar pattern for both osteolytic and osteoblastic subtypes of intraosseous meningiomas and intradural meningioma lesions. MRI allows better definition of the extent of extracranial tumors. PIMs are hypointense on T1-weighted images and hyperintense on T2-weighted images.

Homogeneous enhancement after Gadolinium (Gd) administration is typical. The "dural tail" often found with intradural meningiomas is usually missing in intraosseous meningiomas, but Gd enhancement of the dura may be present and could be secondary to inflammation or tumour infiltrative processes.

The MRI allows the distinction of intraosseous meningioma from other osteolytic lesions such as haemangioma, eosinophilic granuloma (which are nonenhancing), aneurysmal bone cyst (multiloculated with fluid levels), and epidermoid/dermoid (fat contents). Plasmacytoma or multiple myeloma are associated with anaemia and an monoclonal band in serum protein electrophoresis.

Brown tumours shows usually hyperparathyroidism. Malignant lesions such as metastases, chondrosarcoma and osteosarcoma are often suspected by clinical factors such as known primary cancer, rapid growth pattern or by specific radiographic features (multiple lesions, ragged margins without sclerosis).

Intraosseous meningioma with osteolytic features have a higher probability of malignancy compared with the osteoblastic ones.

\subsection{Treatment}

Extended surgical excision of intraosseous meningiomas is the treatment of choice and is potentially curative. ${ }^{[2,23]}$ If a total resection is not achievable, decompression of nerves and vital structures should be performed. Extended tumour resection and skull remodelling are other crucial treatment aspects. Ideally, cranioplasty should be performed in the same procedure. ${ }^{[20]}$

Postoperative CT or MRI imaging should be performed to evaluate the extent of resection and follow-up should be performed in order to monitor tumour recurrence or progression. Most of these tumours are histologically benign, but they may affect certain parts of the skull base not amenable to complete resection. Patients with benign tumours that cannot be resected radically and are neurologically asymptomatic may be followed-up using serial imaging. ${ }^{[22]}$

Additional treatment may be considered for those cases in which patients present with neurological deficits, or where a complete resection is not achievable, or in histologically malignant lesions. External beam or stereotactic radiosurgery, chemotherapy, and bisphosphonate therapy are most frequently proposed options.

In the literature adjuvant radiation therapy is recommended in incompletely resected lesions or when the residual lesion shows radiographic evidence of progression or causes symptomatic compression of the adjacent structures. ${ }^{[22,24,25]}$

Despite their benign nature, ossifying meningiomas of the skull base represent both a diagnostic and therapeutic challenge, especially in the presence of diffuse unresectable lesions where treatment options are limited and palliative.

\section{Conclusion}

We reported this rare case of intraosseous meningioma to illustrate the importance of an adequate differential diagnosis in order to reach a correct diagnosis and avoid erroneous treatment. PIMs are an extremely rare entity. It accounts for less than $1 \%$ of all bone tumors and may be easily mistaken with fibrous dysplasia because both lesions present with similar radiologic and histologic features. Immunohistochemistry is a valuable tool in differentiating the two entities.

\section{Conflicts of Interest Disclosure}

The authors declare no conflicts of interest. 


\section{REFERENCES}

[1] Kulali A, Ilcayto R, Rahmanli O. Primary calvarial ectopic meningiomas. Neurochirurgia. 1991; 34: 174-7. http://dx.doi.org/1 $0.1055 / \mathrm{s}-2008-1052084$

[2] Oka K, Tomonaga M, Hirakawa K, et al. Primary calvarial meningiomas, in: Schmidek HH (ed): Meningiomas and their Surgical Management. Philadelphia. WB Saunders. 1991; 191-202. PMid: 1957644.

[3] Siegel GJ, Anderson PJ. Extracalvarial meningioma: Case report. J Neurosurg. 1966; 25: 83-6. PMid: 5947052. http://dx.doi.org /10.3171/jns.1966.25.1.0083

[4] Lopez DA, Silvers DN, Helwig EB. Cutaneous meningiomas: a clinicopathological study. Cancer. 1974; 34: 728-44. http://dx.doi.org/10.1002/1097-0142(197409)34: 3<728: :AID-CNCR2820340332>3.0.CO;2-U

[5] Karp LA, Zimmerman LE, Borit A, et al. Primary intraorbital meningiomas. Arch Ophthalmol. 1974; 91: 24-8. PMid: 4202807. http: //dx.doi.org/10.1001/archopht.1974.03900060028007

[6] Sadasivan B. Ectopic meningiomas, in: Schmidek HH (ed): Meningiomas and Their Surgical Management. Philadelphia, WB Saunders. 1991; 493-9.

[7] Mori S, Kobayashi S, Miki H, et al. Extracranial meningioma in the parapharyngeal space. Acta Pathol Jpn. 1993; 43: 130-4. http: //dx.doi.org/10.1111/j.1440-1827.1993.tb01121.x

[8] Ibrahim AW, Satti MB, Ibrahim EM. Extraspinal meningioma: Case report. J Neurosurg. 1986; 64: 328-30. PMid: 3944646. http: //dx.doi.org/10.3171/jns.1986.64.2.0328

[9] Malca SA, Roche PH, Thomassin JM, et al. Une tumeur cervicale inhabituelle: le meningiome. A propos d'un cas d'origine pétreuse. Revue de la littérature du méningiome se présentant comme une masse cervicale. Neurochirurgie. 1994; 40: 96-108. PMid: 7870252.

[10] Daugaard S. Ectopic meningioma of a finger: Case report. J Neurosurg. 1983; 58: 778-80. PMid: 6834129. http://dx.doi.org/10. 3171/jns. 1983.58.5.0778

[11] Perzin KH, Pushparaj N. Non-epithelial tumors of the nasal cavity, paranasal sinuses and nasopharynx: a clinicopathological study. XIII. Meningiomas. Cancer. 1984; 54(9). http://dx.doi.org/10.1002/1097-0142(19841101)54: 9<1860: : AID-CNCR2820540916>3.0.CO;2-9

[12] Thompson LDR, Gyure KA. Extracranial sinonasal tract meningiomas: a clinicopathologic study of 30 cases with a review of the literature. The American Journal of Surgical Pathology. 2000; 24(5): 640-50. PMid: 10800982. http://dx.doi.org/10.1097/00000 478-200005000-00002
[13] Louis DN, Hiroko O, Wiestler OD, et al. The 2007 WHO classification of tumors of the central nervous system. Epub 2007Jul 64 th ed. 97-109

[14] Changhong L, Naiyin C, Yuehuan, et al. Primary intraosseous meningioma of the skull. Clin Radiol. 1997; 52: 546-50. http: //dx.doi.org/10.1016/S0009-9260(97)80333-9

[15] Daffner RH, Yakulis R, Marron JC. Intraosseous meningioma. Skeletal Radiol. 1998; 27: 108-11. PMid: 9526778. http://dx.doi.o $\mathrm{rg} / 10.1007 / \mathrm{s} 002560050347$

[16] Agrawal V, Ludwig N, Agrawal A, et al. Intraosseous intracranial meningioma. AJNR Am J Neuroradiol. 2007; 28: 314-5. PMid: 17297003.

[17] Kudo H, Maeda S, Takamoto T, et al. Intraosseous meningioma with a dural defect. Neurol Med Chir. 1998; 38: 229-31. http: //dx.doi.org/10.2176/nmc.38.229

[18] Okamoto S, Hisaoka A, Aoki T, et al. Intraosseous microcystic meningioma. Skeletal Radiol. 2000; 29: 354-7. PMid: 10929419. http://dx.doi.org/10.1007/s002560000217

[19] Rosahl SK, Mirzayan MJ, Samii M, et al. Intra-osseous meningiomas: illustrated review. Acta Neurochir. 2004; 146: 1245-9. PMid: 15349760. http://dx.doi.org/10.1007/s00701-004 $-0380-7$

[20] Tokgoz N, Oner YA, Kaymaz M, et al. Multiple meningioma associated with intraosseous and tentorial meningioma. Case report, Mo To Shinkei. 1994; 46: 884-8.

[21] Jayaraj K, Martinez S, Freeman A, et al. Intraosseous meningiomaa mimicry of Paget's disease? J Bone Miner Res. 2001; 16: 1154-6. PMid: 11393793. http://dx.doi.org/10.1359/jbmr.2001.1 6.6.1154

[22] Crawford TS, Kleinschmidt-DeMasters BK, Lillehei KO. Primary intraosseous meningioma: Case report. J Neurosurg. 1995; 83: 912-5. PMid: 7472564. http://dx.doi.org/10.3171/jns.1995.83 .5 .0912

[23] Hoye SJ, Hoar CS Jr, Murray JE. Extracranial meningioma presenting as a tumor of the neck. Am J Surg. 1960; 100: 486-9. http://dx.doi.org/10.1016/0002-9610(60)90394-9

[24] Lang FF, MacDonald K, Fuller GN, et al. Primary extradural meningiomas: a report on nine cases and review of the literature from the era of computerized tomography scanning. J Neurosurg. 2000; 93 : 940-50. PMid: 11117866. http://dx.doi.org/10.3171/jns.2 000.93 .6 .0940

[25] Partington MD, Scheithauer BW, Piepgras DG. Carcinoembryonic antigen production associated with an osteolytic meningioma: Case report. J Neurosurg. 1995; 82: 489-92. PMid: 7861230. http: //dx.doi.org/10.3171/jns.1995.82.3.0489 